\title{
A Role of Netrin-1 in the Formation of the Subcortical Structure Striatum: Repulsive Action on the Migration of Late-Born Striatal Neurons
}

\author{
Tadashi Hamasaki, Satoshi Goto, Shigeyuki Nishikawa, and Yukitaka Ushio \\ Laboratory of Neurobiology, Department of Neurosurgery, Kumamoto University Medical School, \\ Kumamoto 860-8556, Japan
}

\begin{abstract}
The mammalian striatum arises in the basal telencephalon and contains morphologically homogenous neurons that can be divided into two distinct compartments, patches and the matrix. During development, patch neurons are generated first to form a striatal primordium. After a large influx of later-born matrix neurons into this region, the unique mosaic arrangement of these two neuronal phenotypes is established. The massive migration of matrix neurons continues during the embryonic period, and they eventually comprise $80-85 \%$ of the mature striatum. To elucidate the cellular mechanism or mechanisms underlying this critical event in striatal histogenesis, we examined the migration characteristics of striatal subventricular zone (SVZ) cells at embryonic day 18 when neurogenesis peaks for matrix neurons. Using gel cultures, we show that netrin-1, one of the diffusible guidance cues expressed in the striatal ventric-
\end{abstract}

The mammalian striatum receives inputs from broad regions of the cerebral cortex and provides the vital component of the basal ganglia circuit involved in motor, cognitive, and emotional functions (Alexander and Crutcher, 1990; Graybiel, 1990; Gerfen, 1992). The striatum lacks prominent cytoarchitectures such as cortical lamination. However, its morphologically homogenous neurons (Bishop et al., 1982) can be divided into two distinct compartments arranged in a mosaic manner, patches and matrix (Graybiel, 1990; Gerfen, 1992). The neurons of these two compartments are generated during mainly nonoverlapping developmental stages (van der Kooy and Fishell, 1987). In rats, the patch neurons are generated first, beginning at embryonic day 13 (E13); they form the postmitotic region in the lateral ganglionic eminence (LGE) (Fig. 1A) (van der Kooy and Fishell, 1987). After E16, a massive wave of later-generated matrix cells originating primarily from the striatal subventricular zone (SVZ) flows into the striatal primordium and divides the patch neurons into clusters (Fig. 1B) (van der Kooy and Fishell, 1987). As this large influx of matrix cells continues during the embryonic period, these cells end up comprising $80-85 \%$ of the mature striatum

Received Oct. 17, 2000; revised Feb. 23, 2001; accepted March 21, 2001.

This work was supported by a grant-in-aid for Scientific Research from the Ministry of Education, Science, and Culture of Japan. We thank Dr. Ryuichi Shirasaki of the Salk Institute for providing the netrin-1-secreting HEK293 EBNA cell line, for technical advice, and for critical suggestions, and Dr. Marc TessierLavigne of the University of California, San Francisco for approving our use of the cell line.

Correspondence should be addressed to Dr. Satoshi Goto, Department of Neurosurgery, Kumamoto University Medical School, Honjo 1-1-1, Kumamoto 8608556, Japan. E-mail: sgoto@kaiju.medic.kumamoto-u.ac.jp.

Copyright (C) 2001 Society for Neuroscience $0270-6474 / 01 / 214272-09 \$ 15.00 / 0$ ular zone (VZ), exerts a repulsive action on migrating SVZ cells. This effect is blocked in the presence of antibodies against Deleted in colorectal cancer (DCC), a putative receptor for netrin-1. The expression patterns of netrin-1 and DCC strongly suggest the involvement of this effect in the outward migration of SVZ cells into the striatal postmitotic region. Our cell tracing study using living brain slices demonstrates that striatal SVZ cells migrate toward and disperse throughout the striatum, in which they differentiate into phenotypes of striatal projection neurons. We suggest that netrin-1 expressed in the striatal VZ serves to guide the large influx of striatal matrix neurons into the striatal primordium and is thereby involved in the initial formation of fundamental striatal structures.

Key words: DCC; gel culture; matrix neuron; netrin-1; neuronal migration; outward migration; repulsion; striatum; SVZ
(Fig. 1C) (Johnston et al., 1990). In mutant mice lacking $d l x 1 / 2$ homeobox genes, the matrix neurons are unable to migrate out of the SVZ, resulting in severe structural abnormalities of the striatum (Anderson et al., 1997b). The matrix cell influx is thought to play a critical role in the establishment of the basic organization of the striatum; however, the cellular and molecular mechanisms underlying this process are still poorly understood.

There is a growing body of evidence that molecular guidance cues in the environment are required for the establishment of the highly stereotyped organization of the nervous system (TessierLavigne and Goodman, 1996; Wu et al., 1999). These cues include proteins that are bound to cellular membranes or the extracellular environment, or soluble proteins that freely diffuse from intermediate or final targets (Tessier-Lavigne and Goodman, 1996). Netrins, one family of these diffusible molecules, serve to guide distinct, developing axons by either attraction or repulsion (Kennedy et al., 1994; Serafini et al., 1994; Colamarino and Tessier-Lavigne, 1995). In addition, recent evidence suggests that members of the netrin family also act as directional guides for neuronal migration (Bloch-Gallego et al., 1999; Yee et al., 1999; Alcantara et al., 2000).

Here we present in vitro experiments demonstrating that the cells migrating out of E18 striatal SVZ explants are repulsively guided by netrin-1. Preferential expression of netrin-1 in the striatal ventricular zone (VZ) and its putative receptor Deleted in colorectal cancer (DCC) (Keino-Masu et al., 1996; Fazeli et al., 1997; Hong et al., 1999) in the SVZ strongly suggest that this repulsive action is involved in the influx of matrix cells to the striatal primordium. In vitro experiments using organotypic slice cultures show that cells that entered into the postmitotic region 
A

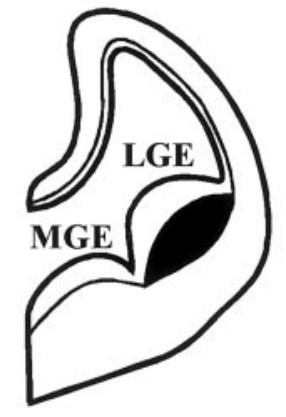

E14

Patch
B

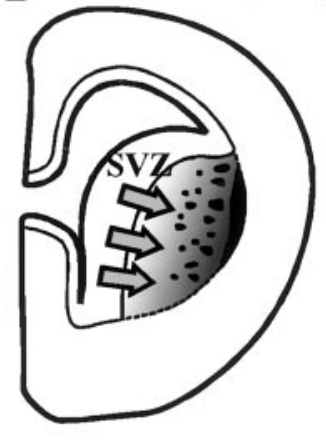

E18

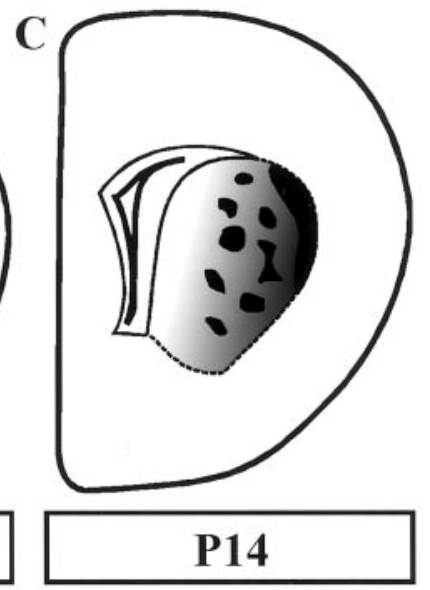

Influx of $\mathbf{m}$ atrix cells
Figure 1. Schematic drawings of coronal telencephalon slices showing the formation of striatal basic structures. Neurons constituting striatal compartments, patches and the matrix, become postmitotic at different embryonic stages. $A$, Striatal patch neurons are born first, beginning at E13. In the basal telencephalon at E14, these neurons form a postmitotic region (black area) in the lateral position of the LGE. B, At E18, the neurogenesis for later-born matrix neurons peaks in the striatal SVZ. The large influx of matrix neurons into the striatal primordium (arrows) penetrates groups of postmitotic patch neurons. These two cell phenotypes are then intermingled with each other in this stage (Krushel et al., 1995), although some clustering of patch neurons is apparent, especially in the lateral position of the postmitotic region. The surge of matrix cell migration is completed before birth. $C$, The compartmentation of patches and the matrix is established shortly after birth. The segregation process is thought to occur because of a selective self-adhesion property of patch neurons (Krushel et al., 1995). After the synaptogenesis period, striatal structures have matured by E14. MGE, Medial ganglionic eminence. appear to differentiate into phenotypic striatal neurons. These findings suggest that the formation of the unique structures of subcortical nuclei is also regulated by an environmental cue commonly present in the developing CNS.

\section{MATERIALS AND METHODS}

Organotypic slice cultures with 1,1',dioctadecyl-3,3,3',3'-tetramethylindocarbocyanine perchlorate. Care of the animals was in accordance with regulations promulgated by the Center for Animal Resources and Development of Kumamoto University. Pregnant Wistar-albino rats were obtained from a commercial vendor (SLC Japan, Shizuoka, Japan), who recorded the morning on which a vaginal plug was detected as E0. Pregnant dams with E18 embryos were placed under deep fluothane gas anesthesia, and their embryos were removed by midline laparotomy. Brains were dissected out from the embryos and cut into $300 \mu \mathrm{m}$ slices using a McIlwain tissue chopper (Mickle Laboratory Engineering Co. Ltd., Gomshall, UK). Slices through the midstriatum were kept in ice-cold dissecting medium [100\% DMEM-F-12 (Life Technologies, Gaithersburg, MD) with $3.85 \mathrm{mg} / \mathrm{ml}$ glucose, $\mathrm{pH}$ 7.35]. The fluorescent lipophilic carbocyanine dye 1,1', dioctadecyl-3,3,3',3'-tetramethylindocarbocyanine perchlorate (DiI) (Molecular Probes, Eugene, OR) was injected into the SVZ of the LGE (see Fig. 6A) (Honig and Hume, 1986). The slices were then transferred onto a collagen-coated membrane (Transwell-COL 3491; Coster, Tokyo, Japan) and incubated in culture medium $[15.6 \mathrm{mg} / \mathrm{ml}$ DMEM-F-12 medium containing $10 \%$ heat-inactivated fetal bovine serum (HI-FBS), 1\% N2 supplement (Life Technologies), $1.2 \mathrm{mg} / \mathrm{ml} \mathrm{NaHCO} 3,10 \mathrm{~mm}$ 2-mercaptoethanol, and 3.85 $\mathrm{mg} / \mathrm{ml}$ glucose, $\mathrm{pH}$ 7.2]. Penicillin $(100 \mathrm{U} / \mathrm{ml})$ and streptomycin $(100$ $\mathrm{mg} / \mathrm{ml}$ ) were added. The culture plates were placed in an incubator at $37^{\circ} \mathrm{C}$ in a $5 \% \mathrm{CO}_{2}$-enriched moist atmosphere. The medium was changed twice per week. After $4 \mathrm{~d}$, the slices were fixed with ice-cold $4 \%$ paraformaldehyde in $0.1 \mathrm{M}$ phosphate buffer (PB), pH 7.4, at $4^{\circ} \mathrm{C}$ overnight. DiI-labeled cells in the striatal area (see Fig. $6 \mathrm{~A}$, dark gray area) and in the neocortical area (see Fig. 6 A, light gray area) were counted under an epifluorescent microscope (BX-80; Olympus Optical, Tokyo, Japan) and recorded as the percentage of total cell count. Fluorescent images were obtained using a confocal laser-scanning microscope (Fluoview; Olympus Optical).

Preparation of cell aggregates. A netrin-1-secreting human embryonic kidney 293 (HEK293)-Epstein-Barr virus-encoded nuclear antigen (EBNA) cell line and the parental HEK293-EBNA cell line were gifts from Dr. R. Shirasaki (Salk Institute, La Jolla, CA). Maintenance of the cell lines and preparation of the cell aggregates were according to the methods of Shirasaki et al. $(1995,1996)$. After incubating the hanging drop cultures (Kennedy et al., 1994) for $18-24 \mathrm{hr}$, cell aggregates were harvested into warm DMEM-F12 medium containing 10\% HI-FBS, cut into pieces with a surgical knife, and immediately placed in gel culture.

Gel cultures. Explants (200 $\mu \mathrm{m}$ in diameter) were dissected out from the striatal SVZ of E18 coronal brain slices (i.e., from the same position at which the DiI was injected in Fig. $6 A$ ). These procedures were performed under a surgical microscope using a surgical knife and for- ceps. SVZ explants were placed beside (separation, 200-500 $\mu \mathrm{m}$ ) trimmed aggregates of netrin-1-HEK293-EBNA cells or HEK293EBNA cells in a 1:1 mixture of collagen gel (Nitta Gelatin Inc., Osaka, Japan) and Matrigel, a three-dimensional extracellular matrix gel of collagen IV, laminin, heparin sulfate proteoglycans, and entactin-nidogen (Becton Dickinson, Bedford, MA). The explants were then cultured with the same medium under the conditions described above. For the blocking experiments, anti-DCC antibody (Oncogene Research Products, Cambridge, MA) or control mouse IgG solutions (Sigma, St. Louis, MO) were added to the culture after they were dialyzed against DMEMF12 medium (Keino-Masu et al., 1996). After $24 \mathrm{hr}$ in vitro, cultured tissues were photographed in phase contrast and then fixed by overnight immersion in $4 \%$ paraformaldehyde in $0.1 \mathrm{M} \mathrm{PB}$ at $4^{\circ} \mathrm{C}$.

Cell proliferation study. Pregnant dams (E18) were injected with a single pulse $(30 \mathrm{mg} / \mathrm{kg}$ body weight, i.p. ) of 5-bromo-2-deoxyuridine (BrdU) $(10 \mathrm{mg} / \mathrm{ml}$ dissolved in saline; Nacalai Tesque, Kyoto, Japan). After $3 \mathrm{hr}$, the embryonic brains were harvested and fixed as described above. Cryostat sections $(10 \mu \mathrm{m})$ were cut and mounted on MAS-coated slides (Asaki Techno Glass, Tokyo, Japan). These were first incubated in $2 \mathrm{~N} \mathrm{HCl}$ for $90 \mathrm{~min}$ and in PBS, $\mathrm{pH} 8.5$, for $30 \mathrm{sec}$ to neutralize the $\mathrm{HCl}$ and then immunostained for BrdU.

Tissue preparation. For in vivo studies, E18 rat embryos were dissected out as described above and perfused transcardially with $0.9 \%$ saline in $0.01 \mathrm{M}$ PBS, $\mathrm{pH} 7.4$, and then with ice-cold $4 \%$ paraformaldehyde in 0.1 M PB. The brains were removed, post-fixed overnight with the same fixative at $4^{\circ} \mathrm{C}$, and then kept overnight at $4^{\circ} \mathrm{C}$ in $0.1 \mathrm{M} \mathrm{PB}$ containing $30 \%$ sucrose for cryoprotection. On the following day, the brains were embedded in OCT compound (Sakura Finetechnical, Tokyo, Japan) and frozen in dry-ice-acetone. Cryostat sections $(40 \mu \mathrm{m})$ were cut and kept in PBS. For immunostaining studies of organotypic slice cultures, the fixed tissues were processed in the same way.

Immunofluorescence staining. Rabbit polyclonal antibody to striatal enriched protein tyrosine phosphatase (STEP) (Oyama et al., 1995), rabbit polyclonal antibody to calcineurin (CaN) (Goto et al., 1987), rabbit polyclonal antibody to glutamate decarboxylase with an $M_{\mathrm{r}}$ of $67,000\left(\mathrm{GAD}_{67}\right)$ (Chemicon, Temecula, $\left.\mathrm{CA}\right)$, mouse monoclonal antibody to $\beta$-tubulin isotype III (TuJ1) (Sigma), mouse monoclonal antibody to BrdU (Sigma), and mouse monoclonal antibody to DCC (Oncogene Research Products) were used as primary antibodies. The sections were blocked with $3 \%$ bovine serum albumin (BSA)-PBS for $1 \mathrm{hr}$ and then incubated overnight at $4^{\circ} \mathrm{C}$ in $3 \%$ BSA-PBS containing primary antibodies. Immunoreactivity was detected by FITC- or Texas Redconjugated secondary antibodies. TuJ1-immunostained or DCCimmunostained, whole-mount tissues embedded in gel were further incubated in propidium iodide (PI) solution for $5 \mathrm{~min}$ at room temperature for nuclear staining. The fluorescence activities were observed and recorded under a confocal laser-scanning microscope (Fluoview; Olympus Optical), and the images were printed using Pictrography 3000 (Fujifilm, Tokyo, Japan). Cross-reactivity between the individual immunoreagents was tested by cross-fluorescence controls.

In situ hybridization. Two oligonucleotide probes (AAG GTT GCA GTT GCA GGC CAC GCA CTC GTT GGC CTC GCG AGC CGT and 

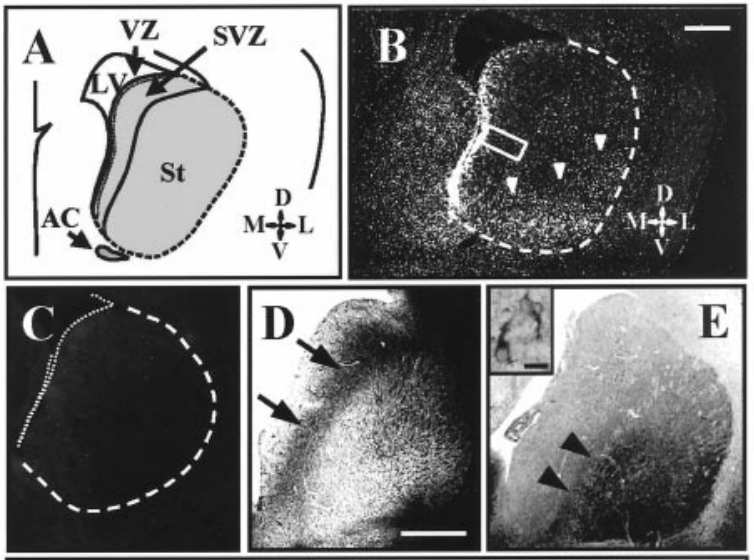

VZ
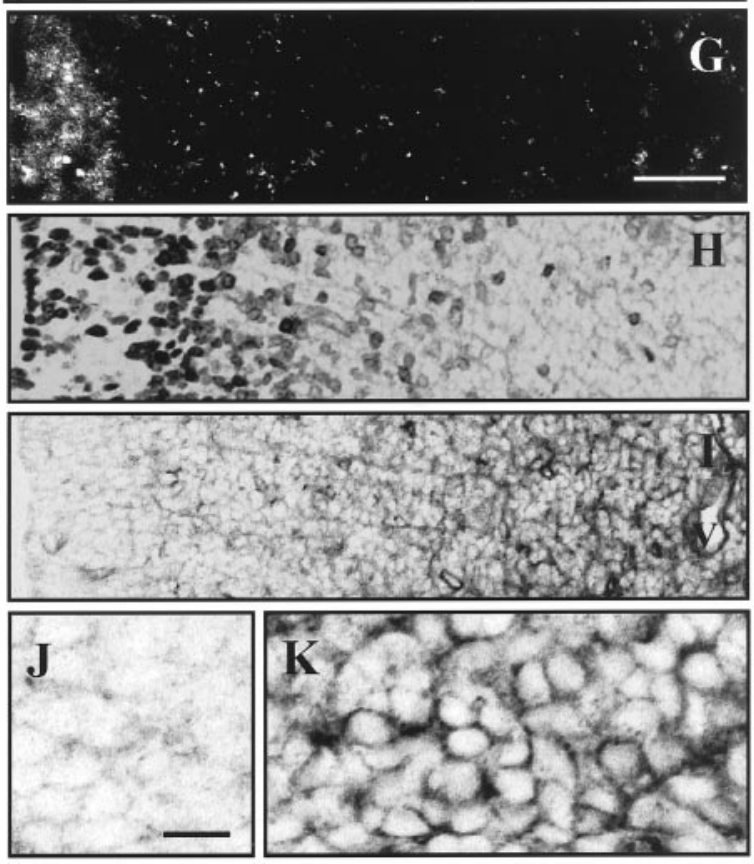

Figure 2. Expression patterns of rat netrin-1 and its receptor DCC in the E18 striatum. $A$, Schematic drawing of a coronal section of E18 rat brain at the midstriatal level. $B, C$, Negative prints of in situ hybridization using rat netrin- 1 oligonucleotide probes $(B)$ and the control probe $(C)$ taillabeled with digoxigenin. netrin-1 is strongly expressed in the striatal VZ $(B)$. Expression is also detected throughout the striatal postmitotic area, especially in the ventrolateral region (arrowheads in $B$ ). The dashed line indicates the striatal primordium. The dorsal side of the brain is to the top. $D$, DCC immunostaining of the E18 striatum. Immunoreactivity is distributed in the SVZ (arrows). In the striatal postmitotic area, DCC immunoreactivity is found only in the intrastriatal axon bundles but not in the striatal cells. $E, \mathrm{GAD}_{67}$ immunostaining of the E18 striatum. Immunoreactivity is prominently found in the ventrolateral position of the striatal area (arrowheads). The site of the expression appears to correspond with that of the netrin-1 expression shown in $B$. The inset shows examples of $\mathrm{GAD}_{67}$-positive cells observed in the ventrolateral position of the E18 striatum. $F$, The extent of the VZ and the SVZ in $G-I$. The right edge of this drawing is near the SVZ/striatum border. Dashed boxes indicate the sites of observation in $J$ and $K$. $G$, Higher magnification of boxed area in $B$. Although there is strong expression in the VZ, the striatal SVZ is almost devoid of expression. $H$, BrdU staining in the same area indicated by a box in $B 3 \mathrm{hr}$ after the single injection of BrdU. The labeled cells are located in the VZ and in the medial region
CCC GCT CTT GCG CCC TGA TAG CTT GTA AAG CTC CAT GTT GAA TCT) were synthesized according to the partial sequence of rat netrin-1 (Livesey and Hunt, 1997). An oligonucleotide sequence homologous to the lacZ region in pUC and M13 plasmids (TTG GGT AAC GCC AGG GTT TTC CCA GTC ACG) was used as the control probe. These probes were enzymatically tailed at their $3^{\prime}$ end with a digoxigenin (DIG)-labeled dUTP using the DIG Oligonucleotide Tailing kit (Boehringer Mannheim, Mannheim, Germany) according to the instructions of the manufacturer. Hybridization histochemistry was performed according to the method of Nomura (1994) with a few modifications. We cut $10-\mu \mathrm{m}$-thick coronal cryostat sections of the midstriatum from freshly frozen E18 rat brain and mounted the sections on slides coated with 3-aminopropyltriethoxysilane (Sigma). These sections were fixed by a $30 \mathrm{~min}$ immersion in ice-cold $4 \%$ paraformaldehyde in PBS and then incubated as follows: $2 \mathrm{~min}$ in $2 \mu \mathrm{g} / \mathrm{ml}$ proteinase $\mathrm{K}$ in $10 \mathrm{~mm}$ Tris- $\mathrm{HCl}, \mathrm{pH} 8.0$, and $1 \mathrm{~mm}$ EDTA; $10 \mathrm{~min}$ in $4 \%$ paraformaldehyde in PBS; $10 \mathrm{~min}$ in $0.2 \mathrm{~N} \mathrm{HCl} ; 1 \mathrm{~min}$ in $0.1 \mathrm{M}$ triethanolamine- $\mathrm{HCl}$ (TEA), pH 8.0; and $10 \mathrm{~min}$ in $0.1 \mathrm{M} \mathrm{TEA}$ and $0.25 \%$ acetic anhydrate. To reduce nonspecific binding of probes, sections were prehybridized for $1 \mathrm{hr}$ at $42^{\circ} \mathrm{C}$ in hybridization buffer $(50 \%$ formamide, $10 \mathrm{~mm}$ Tris- $\mathrm{HCl}, \mathrm{pH} 7.6$, $200 \mu \mathrm{g} / \mathrm{ml}$ tRNA, $1 \times$ Denhardt's solution, $10 \%$ dextran sulfate, $600 \mathrm{~mm}$ $\mathrm{NaCl}, 0.25 \% \mathrm{SDS}$, and $1 \mathrm{~mm}$ EDTA, $\mathrm{pH} 8.0)$. A total of $1.0 \mathrm{pmol}(0.5$ pmol each) of DIG-labeled probes per $50 \mu$ l of hybridization buffer was then applied to each slide. The sections were then incubated in a humid chamber for $20 \mathrm{hr}$ at $42^{\circ} \mathrm{C}$. Thereafter, sections were washed for $1 \mathrm{hr}$ in four changes of $1 \times \mathrm{SSC}, \mathrm{pH} 7.2$, at $55^{\circ} \mathrm{C}$ and then soaked for $20 \mathrm{~min}$ at room temperature in two changes of $0.1 \times \mathrm{SSC}$. After rinsing in DIG

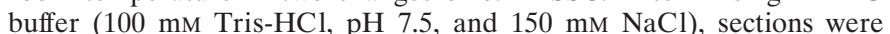
blocked for $1 \mathrm{hr}$ in $3 \%$ normal goat serum in DIG buffer and then incubated overnight at $4^{\circ} \mathrm{C}$ with an alkaline phosphatase-conjugated antibody to digoxigenin (1:2000; Boehringer Mannheim). After washing in DIG buffer, the sections were developed overnight at room temperature with nitroblue tetrazolium and 5-bromo-4-chloro-3-indolyl phosphate (Life Technologies) and then photographed with color reversal films (Sensia II 100; Fujifilm).

Cell counting in gel cultures. Fixed, whole-mount tissues after gel culture were incubated with PI for nuclear staining. These tissues were scanned with a confocal laser in planes at the level of explants every $5 \mu \mathrm{m}$ and then superimposed to obtain a two-dimensional image. The number of PI-stained nuclei in a defined area was recorded and analyzed. To quantitate the effect of netrin-1 on migrating SVZ cells, we used the ratios of cell numbers in proximal (see Fig. 3E, Prox) and distal (see Fig. $3 E$, Dist) areas (P/D ratio; Zhu et al., 1999). Statistical analyses of the data were performed by using the unpaired $t$ test; values of $p<0.05$ were taken as significant.

\section{RESULTS \\ Expression patterns of rat netrin-1 and its receptor DCC in E18 LGE and striatum}

At E18, the neurogenesis of matrix cells in the LGE peaks (van der Kooy and Fishell, 1987); the predominant site of cell proliferation is the SVZ rather than the VZ (Bhide, 1996; Sheth and Bhide, 1997). To test the potential role of netrin-1 as a directional cue for migrating striatal matrix neurons, we examined the localization of netrin-1 expression in the E18 midstriatum (Fig. 2A). Our in situ hybridization study showed that rat netrin-1 expression (Livesey and Hunt, 1997) was prominent in the VZ lining of the LGE and also detected throughout the striatal postmitotic area, especially in the ventrolateral portion (Fig. $2 A, B$; the control is shown in Fig. $2 C$ ). The area of the ventrolateral expression

of the SVZ. I, DCC immunohistochemistry in the same area. Strong immunoreactivity for DCC protein is detected in the lateral position within the SVZ. $J, K$, High magnification of DCC immunohistochemistry in the medial $(J)$ and the lateral $(K)$ position of the striatal SVZ. DCC immunoreactivity appears to be localized in the cell membrane in $K . L V$, Lateral ventricle; St, striatum; $A C$, anterior commissure; $V$, ventral; $D$, dorsal; $M$, medial; $L$, lateral. $V$ (in I), vascular cavity. Scale bars: $B-E, 500$ $\mu \mathrm{m}$; inset in $E, 20 \mu \mathrm{m} ; G-I, 50 \mu \mathrm{m} ; J, K, 20 \mu \mathrm{m}$. 


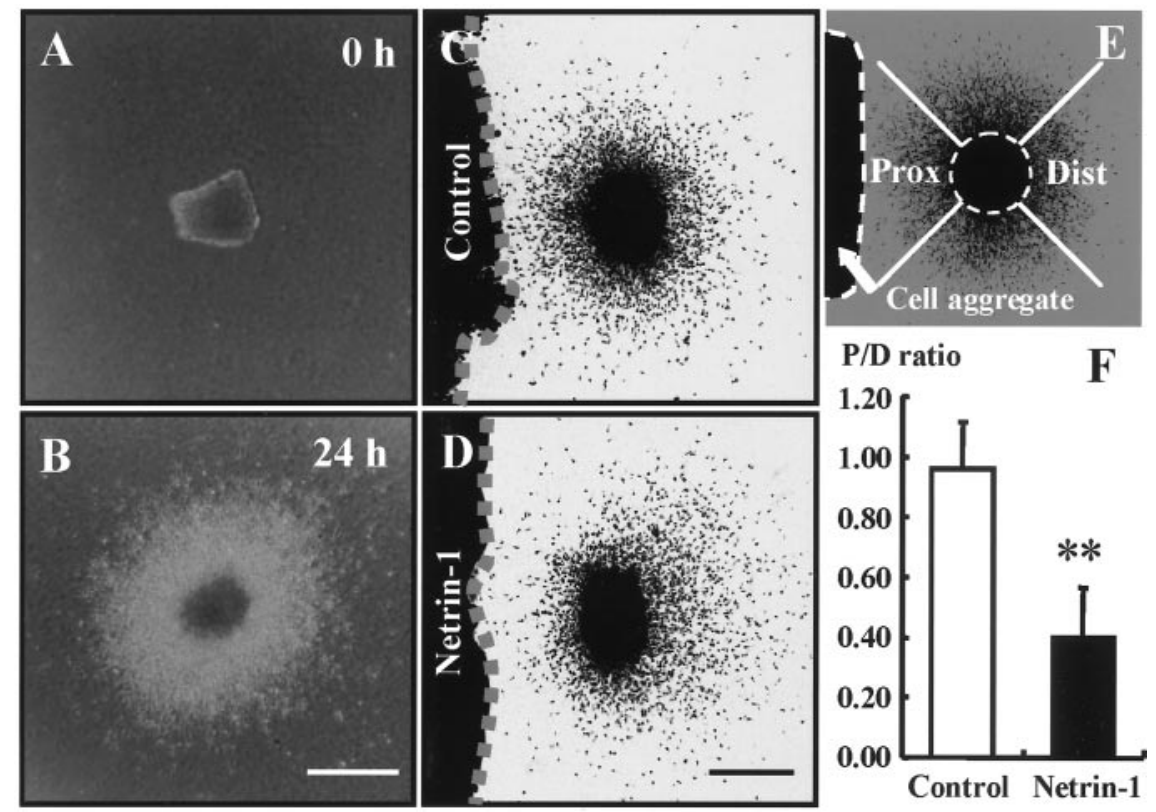

Figure 3. Effect of netrin-1 on E18 striatal SVZ cells in vitro. $A$, A typical example of striatal SVZ explants soon after being embedded in collagen gel containing Matrigel. The edge of the explant is clear. B, After 24 $\mathrm{hr}$ in vitro, a great number of cells have migrated out from the explant. Their distribution exhibits a symmetric pattern. $C$, Example of the SVZ explant cocultured with control cell aggregates. After $24 \mathrm{hr}$ in the collagen gel-Matrigel, whole-mount tissues were stained with PI. The distribution of migrated cells shows the symmetric pattern as seen in $B$. D, Example of the SVZ explant cocultured with netrin-1 cell aggregates under the same culture conditions. The distribution of migrated cells shows a distal bias. $E$, Diagram of defined areas for quantitative analysis. The field around the SVZ explant is divided into four sectors. Prox and Dist indicate quadrants proximal and distal to cell aggregates, respectively. $F$, The ratios of cell numbers in proximal and distal areas (P/D ratio) (Zhu et al., 1999) in the presence of control (white column) or netrin-1 (black column) aggregates. The differences between control and netrin-1 cocultures were statistically significant $(* * p<0.001)$. Scale bars: $A-D, 300 \mu \mathrm{m}$. appeared to correspond with differentiated early-born striatal cells marked by $\mathrm{GAD}_{67}$ immunostaining (Fig. 2E) (Yamada et al., 1996). Compared with the VZ, netrin-1 is expressed only faintly in the SVZ (Fig. $2 F, G$ ).

As an axon guidance receptor for netrin-1, DCC not only mediates chemoattractive actions (Keino-Masu et al., 1996; Fazeli et al., 1997) but is also involved in a chemorepulsive response in vitro by interaction with a second family of netrin- 1 receptors, the UNC5-related protein (Hong et al., 1999). An immunohistochemical study demonstrated cells expressing DCC protein in the SVZ but not in the VZ (Fig. 2D,I). The cells located in the striatal postmitotic area no longer expressed DCC protein (Fig. $2 D$ ), showing that the expression patterns of netrin-1 and DCC were complementary in the developing striatum (Fig. $2 B, D, G, I$ ). Furthermore, the distribution pattern of DCC-expressing cells in the SVZ was biased; they were preferentially located in the SVZ near the striatal postmitotic zone (Fig. $2 F, I-K$ ). The area abundant in DCC immunoreactivity contained few BrdU-positive cells (Fig. 2H,I), suggesting that DCC-positive cells had less proliferative activity. Rather, they appeared ready to migrate out of the germinal zone. Based on these findings, we hypothesized that netrin-1 is involved in the outward migration of striatal SVZ cells.

\section{Repulsive effect of netrin-1 on cells migrating out of SVZ explants}

To directly examine the action of netrin-1 on the migration of striatal SVZ cells, we conducted coculture experiments ( $\mathrm{Hu}$ and Rutishauser, 1996) using transfected HEK293-EBNA cells that are stable in their expression of netrin-1 protein (Shirasaki et al., 1996, 1998). When explants from the E18 striatal SVZ were cultured for $24 \mathrm{hr}$ in the collagen gel containing Matrigel, a large number of migrated cells were symmetrically distributed around the circumference of the explants (Fig. $3 A, B$ ) (Zhu et al., 1999). When the same explants were placed next to aggregates of control HEK293-EBNA cells, the distribution of migrated SVZ cells also exhibited a symmetrical pattern (Fig. $3 C)(n=19$; means of $234 \pm 103$ and $250 \pm 120$ cells in the proximal and distal quadrants, respectively). In contrast, migrating SVZ cells were asymmetrically distributed around the explants when cocultured with aggregates of netrin-1-expressing HEK293-EBNA cells; there were more cells in the distal than the proximal quadrant (Fig. $3 D)(n=31$; means of $130 \pm 63$ and $354 \pm 160$ cells in the proximal and distal quadrants, respectively). Totals of mean numbers of cells counted in the control and netrin-1 cultures were both 484 , suggesting that netrin-1 does not cause the SVZ cells to proliferate. The effect of netrin-1 on migrating SVZ cells was quantified both spatially and numerically by the P/D ratios (Materials and Methods; Fig. $3 E$ ). Our results were $0.96 \pm 0.16$ (Fig. $3 F$, white column) and $0.40 \pm 0.17$ (Fig. $3 F$, black column) in the control and netrin-1 aggregate cultures, respectively. Netrin-1 could significantly change the distribution of cells migrating out from the striatal SVZ explants $(* * p<0.01)$. This repulsive effect of netrin-1 was reproduced in the collagen gel cultures without Matrigel (data not shown), although it was shown recently that growth cone attraction to netrin-1 of Xenopus retinal neurons is converted to repulsion by laminin-1 (Hopker et al., 1999).

If netrin-1 acts as a chemorepulsive factor on migrating SVZ cells, the cells in the proximal quadrant can be expected to reverse their direction of migration in response to increased concentrations of netrin-1 (Hu and Rutishauser, 1996). To compare the orientation of the leading processes of cells in the proximal quadrant and the distal quadrant, we performed TuJ1 immunostaining with PI staining in the coculture using control (Fig. 4A-D) and netrin-1 (Fig. 4E-J) aggregates. In control cultures, the leading processes of migrating SVZ cells were uniformly oriented away from the SVZ explants in both the proximal (Fig. 4B) and distal (Fig. 4C) sides. In contrast, in cultures with netrin-1 aggregates, the leading processes of cells located in the proximal quadrants were frequently curved back toward the explant (Fig. 4F, striped arrowhead, $H$ ), reversed (Fig. $4 F$, filled arrowhead, I), or collapsed (Fig. $4 F$, open arrowhead, $J$ ). These results demonstrate that netrin-1 acts as a repulsive cue for cells migrating out of the E18 striatal SVZ.

\section{Involvement of DCC receptor in the repulsive action by netrin-1}

In cultures with netrin-1 aggregate, DCC immunostaining showed that the affected cells are DCC-positive (Fig. 5C, filled 

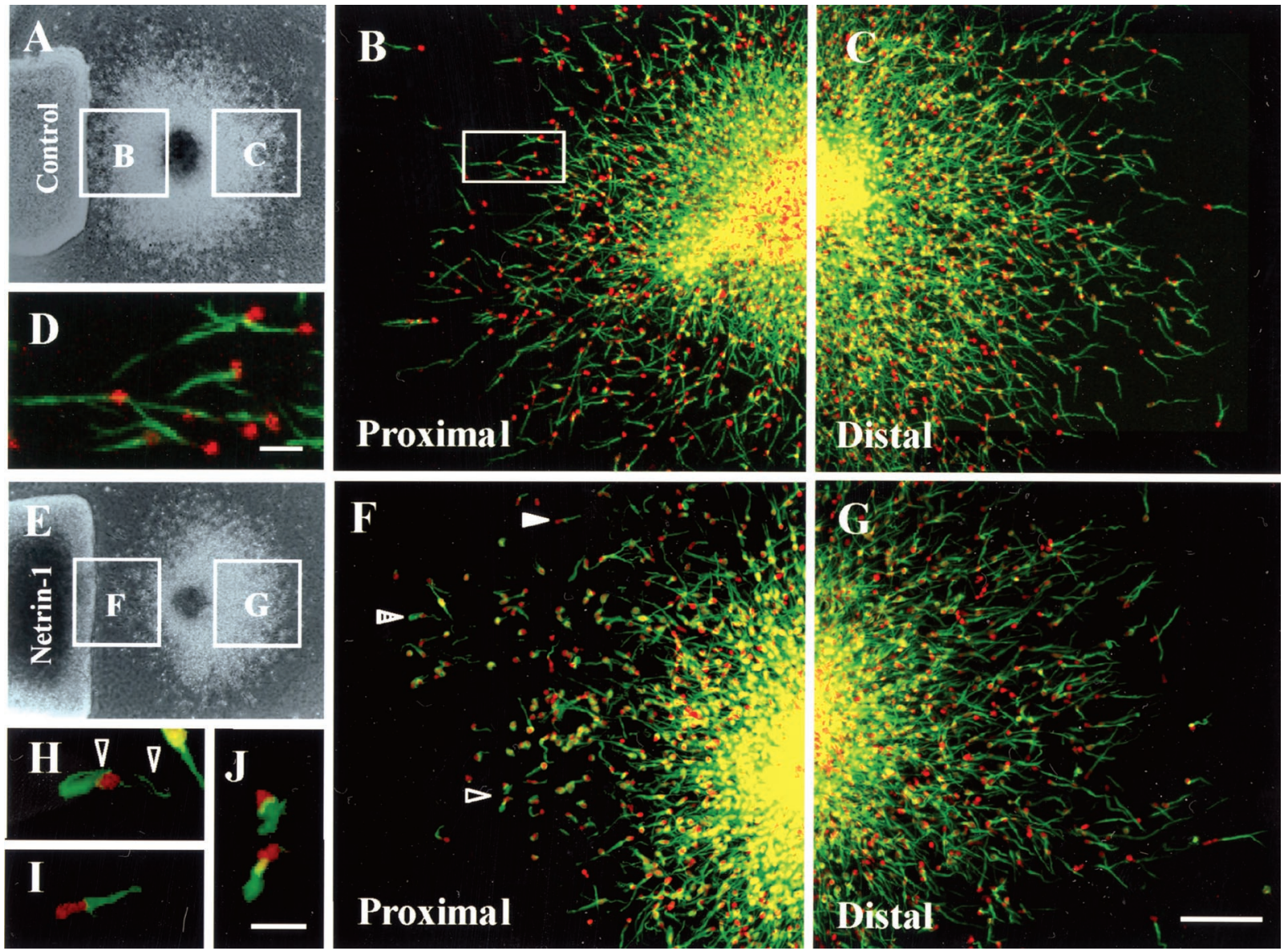

Figure 4. The repulsive action of netrin-1 on migrating SVZ cells. $A$, A phase-contrast photomicrograph showing an example of SVZ explants cocultured with control aggregates (Control) for $24 \mathrm{hr}$. Boxed areas indicate the sites of observation in $B$ and $C$. $B, C$, Whole-mount tissues using control aggregates were immunostained for TuJ1 (green) and also stained for PI (red). Laser scanning photomicrographs showing migrated SVZ cells observed in the proximal $(B)$ and distal $(C)$ fields. In both fields, the cells are widely dispersed with their leading processes oriented away from the SVZ explant. $D$, High magnification of the migrated cells in the boxed area in $B$. The leading processes of these cells are directed toward the control cell aggregate (to the left). E, A phase-contrast photomicrograph showing an example of SVZ explants cocultured with netrin-1 aggregates (Netrin-1) for 24 hr. $F, G$, Whole-mount tissues using netrin-1 aggregates were immunostained for TuJ1 and also stained by PI. The leading processes of cells that migrated near the netrin-1 aggregates $(F)$ exhibit various patterns of orientation, whereas those in the distal field $(G)$ are similar to $B$ or $C$. The cells indicated by arrowheads in $F$ are enlarged in $H-J$. $H-J$, High magnification of the cells indicated in $F$. The leading processes are curved back toward the explant (striped arrowhead in $F ; H$ ), reversed ( filled arrowhead in $F ; I$ ), or collapsed (open arrowhead in $F ; J$ ), suggesting the repulsive action of netrin-1 on the migration of SVZ cells. Scale bars: $B, C, F, G, 100 \mu \mathrm{m} ; D, H-J, 20 \mu \mathrm{m}$.

arrowheads and open arrowhead). To test whether the DCC receptor mediates the repulsive action of netrin-1 on migrating SVZ cells, we conducted blocking experiments using monoclonal antibody against the extracellular domain of DCC (Keino-Masu et al., 1996). In the control experiment, E18 SVZ explants were cocultured with netrin-1 aggregates in the presence of $10 \mu \mathrm{g} / \mathrm{ml}$ normal mouse IgG (Fig. 5D). There were no significant changes in the $\mathrm{P} / \mathrm{D}$ ratios of migrating $\mathrm{SVZ}$ cells with (Fig. $5 F$, black column) ( $n=13$; means of $175 \pm 68$ and $404 \pm 128$ cells in the proximal and distal quadrants, respectively; $\mathrm{P} / \mathrm{D}$ ratio $=0.43 \pm 0.07$ ) or without (Fig. $3 F$, black column) the control serum $(p=0.171$; unpaired $t$ test). In contrast, addition of $1.0 \mu \mathrm{g} / \mathrm{ml}$ (Fig. $5 F$, light gray column $)(n=12$; means of $155 \pm 83$ and $288 \pm 125$ cells in the proximal and distal quadrants, respectively; $\mathrm{P} / \mathrm{D}$ ratio $=0$. $57 \pm 0.29)$ or $10 \mu \mathrm{g} / \mathrm{ml}$ (Fig. $5 F$, white column $)(n=13$; means of $237 \pm 89$ and $292 \pm 108$ cells in the proximal and distal quadrants, respectively; $\mathrm{P} / \mathrm{D}$ ratio $=0.86 \pm 0.33$ ) of an anti-DCC antibody resulted in a dose-dependent increase in the $\mathrm{P} / \mathrm{D}$ ratios (Fig. $5 F)\left({ }^{*} p=0.041<0.05\right.$ between 0.1 and $1.0 \mu \mathrm{g} / \mathrm{ml}$ anti-DCC antibody; ${ }^{*} p=0.014<0.05$ between 1.0 and $10 \mu \mathrm{g} / \mathrm{ml}$ anti-DCC antibody; unpaired $t$ test), although addition of $0.1 \mu \mathrm{g} / \mathrm{ml}$ of the antibody exhibited no significant effect (Fig. $5 F$, dark gray column) ( $n=12$; means of $152 \pm 64$ and $400 \pm 156$ cells in the proximal and distal quadrants, respectively; $\mathrm{P} / \mathrm{D}$ ratio $=0.39 \pm 0.14)(p=$ 0.204 between the control serum and $0.1 \mu \mathrm{g} / \mathrm{ml}$ anti-DCC antibody; unpaired $t$ test). Even at the highest dose (Fig. $5 F$, white column), anti-DCC antibody could not completely block the repulsive effect of netrin-1; however, most of the leading processes of migrated cells in the proximal quadrant appeared oriented away from the explant (Fig. $5 E$, compare with Figs. $4 F, 5 D$ ). These data indicate that DCC function is involved in the repulsive activity of netrin-1 in the migration of striatal SVZ cells.

\section{Distribution patterns and neurochemical character of cells migrating out of the striatal SVZ in the E18 telencephalon}

The LGE at late embryogenesis is the source of neocortical interneurons (Anderson et al., 1997a; Zhu et al., 1999) and of cells distributed in the cortical marginal zone (De Carlos et al., 1996). To examine where striatal SVZ derivatives were predom- 

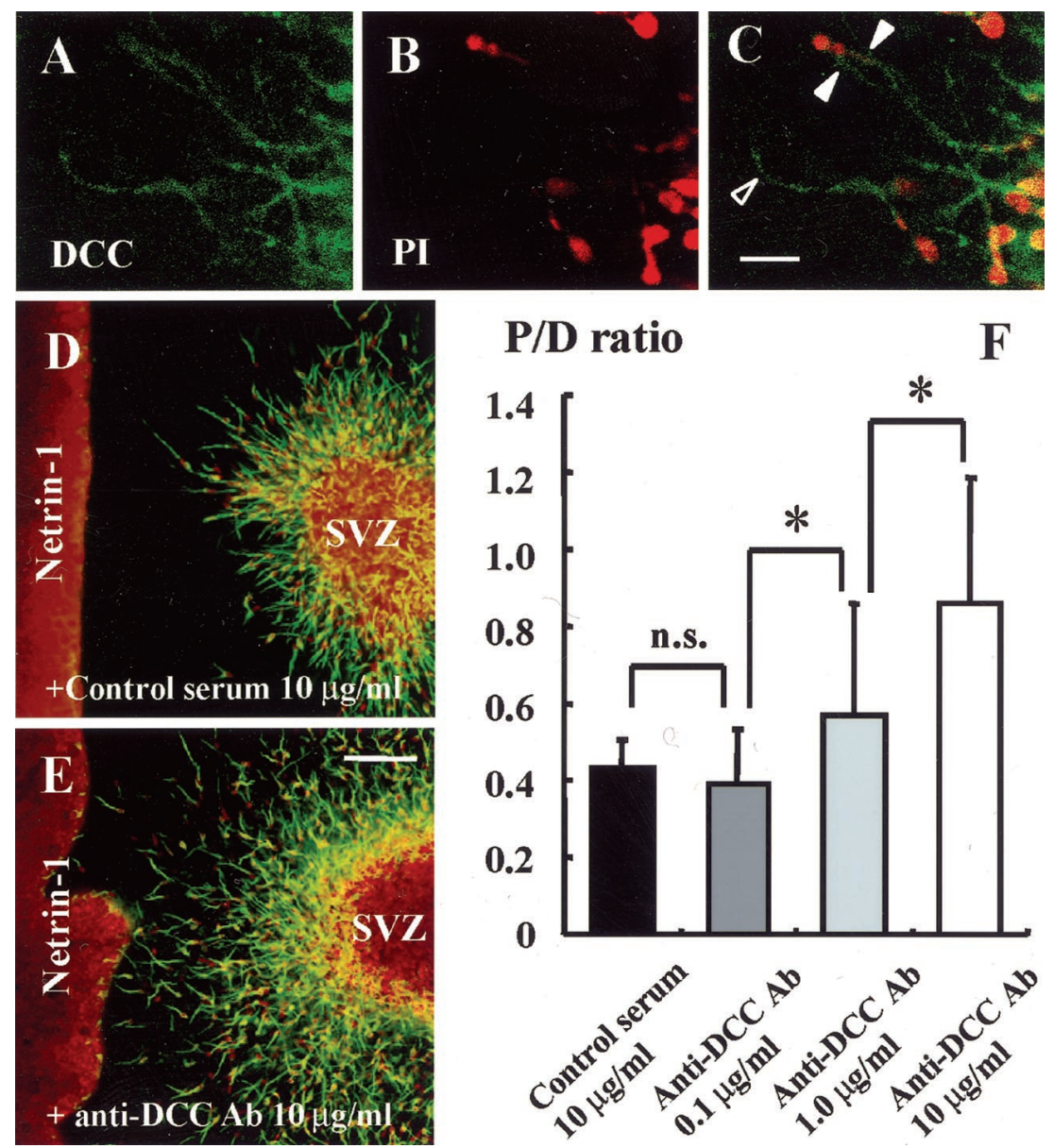

Figure 5. Involvement of DCC function in the repulsive activity of netrin-1. $A-C$, Whole-mount DCC immunostaining of the netrin-1 aggregate culture. DCC immunostaining $(A)$, PI staining $(B)$, and the merged image $(C)$ are shown. The arrowheads in $C$ indicate DCCpositive cells with their leading processes reversed. The open arrowhead indicates a DCC-positive cell with its leading process curved against the netrin-1 source (to the left). D, E, E18 striatal SVZ explants were cocultured with netrin-1 aggregates in gel for $24 \mathrm{hr}$. Whole-mount tissues cultured with the control serum $(D)$ and $10 \mu \mathrm{g} / \mathrm{ml}$ anti-DCC antibody $(E)$ were immunostained for TuJ1 (green) and also stained by PI (red). Most leading processes of cells in $E$ are oriented away from the explants, as shown in Figure $4 B$, suggesting the inhibition of netrin-1-dependent repulsive activity by anti-DCC antibody. $F$, Bar graph showing the blocking effects of antiDCC antibody on netrin-1-dependent repulsion on SVZ cell migration. SVZ explants were cultured with 0.1 $\mu \mathrm{g} / \mathrm{ml}$ (dark gray column), $1.0 \mu \mathrm{g} / \mathrm{ml}$ (light gray column), or $10 \mu \mathrm{g} / \mathrm{ml}$ (white column) anti-DCC antibody or with 10 $\mu \mathrm{g} / \mathrm{ml}$ normal mouse IgG (black column). Data are expressed as average $\pm \mathrm{SE}$ P/D ratios (Fig. $3 E$ ). Error bars indicate SE. ${ }^{*} p<0.05$. n.s., Not significant; $A b$, antibody. Scale bars: $A-C, 20 \mu \mathrm{m} ; D, E, 100 \mu \mathrm{m}$. inantly distributed after their outward migration, we performed a cell-tracing study using organotypic slice cultures. In the beginning of the culture, we injected a small crystal of DiI at the SVZ of the LGE (Fig. 6A, red asterisk). After $4 \mathrm{~d}$, only a few cells labeled with DiI were present in the neocortical region (Fig. $6 B$ ); some were located in the intermediate zone (Fig. 6B, open arrowhead), whereas others had entered into the cortical plate (Fig. $6 B$, filled arrowhead). In contrast, a large number of DiI-labeled cells migrated into and dispersed throughout the striatal area (Fig. 6C). Thus, the cellular output from the striatal SVZ at E18 $(n=18)$ supplies the striatum (a total of 1234 cells; $87.7 \pm$ $7.8 \%$ ) rather than the neocortex (a total of 191 cells; $12.3 \pm$ 7.8\%) (Fig. 6D).

Using immunolabeling methods for the same culture preparations, we characterized the DiI-labeled cells distributed in the striatal area. Most of these cells were immunoreactive for anti$\mathrm{TuJ} 1$ antibody (Fig. $6 E-J$ ), indicating that they exhibit the neuronal phenotype. Immunolabeling studies also showed that the vast majority of DiI-labeled cells was positive for CaN (Fig. $6 K-M)$ and that some of these cells were positive for STEP (Fig. $6 N-P)$. These findings suggest that E18 SVZ cells that migrate into the striatal postmitotic area differentiate into the striatal projection neurons of the medium spinous type (Goto et al., 1994; Oyama et al., 1995).

\section{DISCUSSION}

Our migration assay in gel cultures shows that netrin-1 exerts direct repulsive action on the migration of striatal SVZ cells. The expression patterns of netrin-1 and its receptor DCC strongly suggest the involvement of this guidance cue in the outward migration of striatal SVZ cells. Our cell-tracing study using living brain slices demonstrated that the majority of cellular output from the striatal SVZ supplies the striatum in which SVZ-derived cells differentiate into phenotypic striatal neurons. We suggest that, in the late embryonic stage, netrin-1 expressed in the VZ serves to guide the large influx of striatal matrix neurons into the striatal primordium. It is therefore involved in the initial formation of fundamental striatal structures. This suggestion is strongly supported by the transient expression of netrin-1 in the VZ, primarily in the period of striatal neurogenesis (van der Kooy and Fishell, 1987; Livesey and Hunt, 1997).

\section{Involvement of netrin-1 in the outward migration of late-born striatal cells}

One of the principal events in the initial formation of striatal structures is the large influx of striatal matrix neurons into the postmitotic area (Deacon et al., 1994; Krushel et al., 1995; Sheth and Bhide, 1997). With respect to its direction, this type of cell movement is a form of radial cell migration occurring in the developing basal telencephalon. As in the neocortex (Rakic, 1990), radial glial cells (Misson et al., 1988) may be the guiding substrates for cell migration in the developing striatum (Halliday and Cepko, 1992; De Carlos et al., 1996; Kakita and Goldman, 1999). However, given that the striatum of reeler mice (Lambert de Rouvroit and Goffinet, 1998) and of other mutant mice with neocortical migration disorders lack remarkable structural abnormalities, it is plausible that distinct mechanisms regulate the radial migration observed in striatal development. Study of the 
Figure 6. Distribution patterns and neurochemical character of the cells migrating out of the striatal SVZ in embryonic slices. $A$, Schematic drawing of organotypic culture preparations using E18 coronal brain slices. At the start of culture, a small crystal of DiI (red asterisk) was implanted in the striatal SVZ. After $4 \mathrm{~d}$ in vitro $(4 D I V)$, the neocortical (light gray) and striatal (dark gray) areas were examined. $B$, Typical distribution pattern of DiI-labeled cells found in the neocortical area (boxed area $B$ in $A$ ). The filled arrowhead indicates a DiI-labeled cell that had entered into the cortical plate. The open arrowhead indicates a labeled cell tangentially migrating in the intermediate zone. The dorsal side of the brain is to the top. $C$, Typical distribution pattern of DiI-labeled cells found in the striatal area (boxed area $C$ in $A$ ). In contrast to the neocortical area shown in $B$, many DiI-labeled cells are seen. Most leading processes of these cells are oriented away from the SVZ. D, The numerical density of DiIlabeled cells was quantitatively evaluated as described in Materials and Methods. The white column and the black column indicate the percentages of cell counts in the neocortical (light gray area in $A$ ) and the striatal (dark gray area in $A$ ) regions, respectively, of the total cell counts in these two regions. Error bars indicate the SE. $E-G$, Two examples of DiI-labeled cells $(E)$ immunoreactive for TuJ1 $(F)$. The merged image is shown in $G$. $H-J$, DiI-labeled cells in
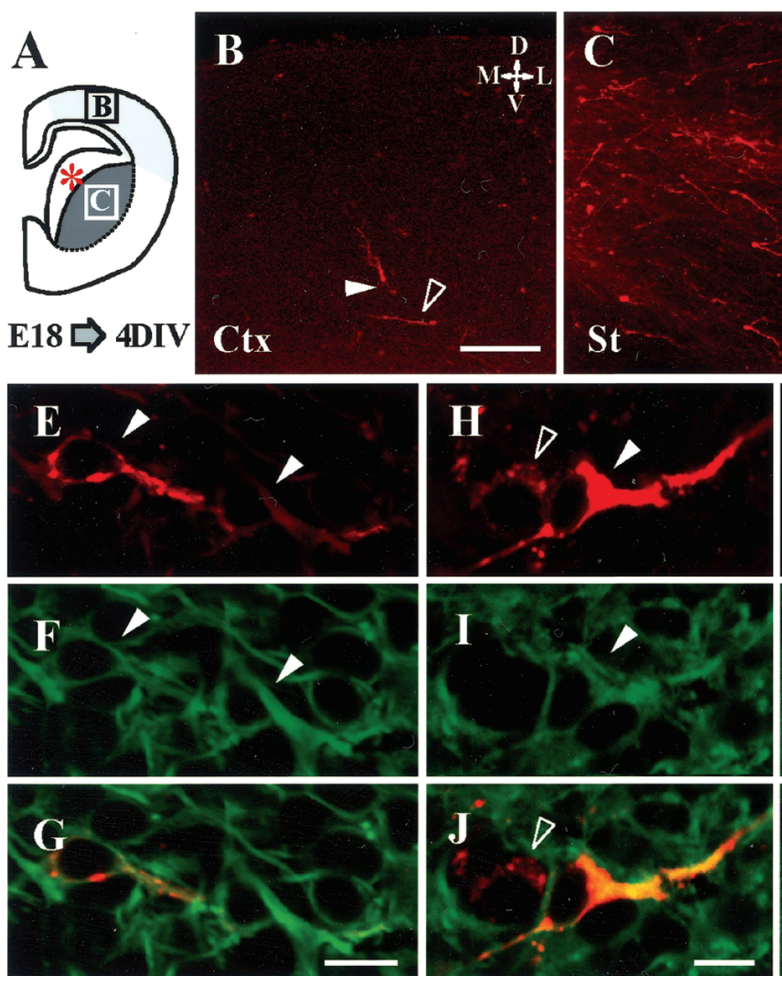
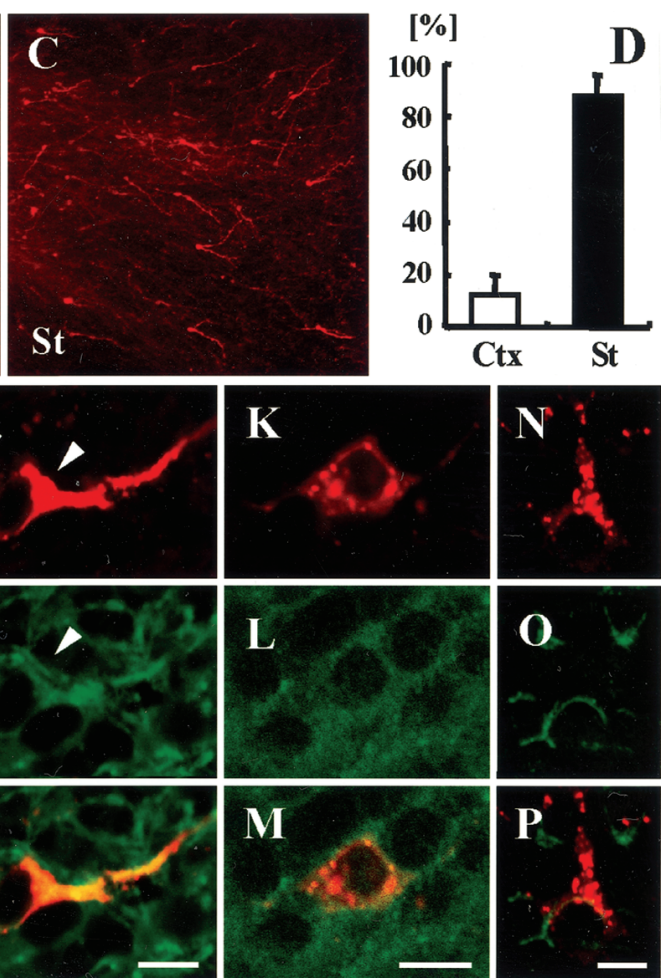

close proximity are cytochemically distinct from each other. Filled arrowheads indicate a DiI-labeled $(H)$, TuJ1-positive $(I)$ cell morphologically similar to striatal medium-sized spinous neurons. Open arrowheads indicate DiI-labeled $(H)$, TuJ1-negative $(I)$ cells; they seem to be glial cells. The merged image is shown in $J . K-M$, An example of DiI-labeled cells $(K)$ immunoreactive for $\mathrm{CaN}(L)$, a marker for the striatal projection neurons of the medium spinous type (Goto et al., 1994). The DiI-labeled cell is intermingled with nonlabeled cells. The merged image is shown in $M$. $N-P$, An example of DiI-labeled cells $(N)$ faintly immunoreactive for STEP $(O)$. The expression is consistent with their cellular identity of striatal projection neurons $(O y a m a$ et al., 1995). The merged image is shown in $P$. Ctx, Cortex; St, striatum; $D$, dorsal; $M$, medial; $L$, lateral; $V$, ventral. Scale bars: $B, C, 200 \mu \mathrm{m} ; E-P$, $10 \mu \mathrm{m}$.

forebrain abnormality in Dlx-1/2 double mutants suggested that the radial migration and differentiation of later-generated striatal neurons are regulated by transcriptional factors (Anderson et al., 1997b). Tangential cell migration from the medial ganglionic eminence has been documented (Sussel et al., 1999; Wichterle et al., 1999); it appears to contribute to supplying the striatum with interneurons (Marín et al., 2000). We found recently that preplate neurons in the paleocortical area migrate radially inward into and disperse within the striatum in the late embryonic stage in rats (Hamasaki et al., 2001). Evidence is thus accumulating that the striatum is organized via plural sets of cell migration; however, the molecular and cellular mechanisms regulating these processes remain poorly understood. Our current study shows that the massive migration of matrix cells into the late embryonic striatum is regulated by one or more environmental cues thought to be involved in the formation of different structures in the developing CNS.

We show that the presence of the anti-DCC antibody can inhibit the repulsive action of netrin-1 in SVZ cell migration in vitro (Fig. 5). Although we have no direct evidence for the involvement of this receptor in vivo, we observed that DCCexpressing cells in the SVZ were located near the striatal postmitotic zone and appeared to be less proliferative (Fig. $2 H, I$ ). This suggests that they may be postmitotic and ready to exit the SVZ. This hypothesis is supported by the observations of Gad et al. (1997) who showed that, in mice, DCC mRNA expression was initiated in recently born neurons migrating out of the proliferative zone and was downregulated in mature structures throughout the early brain. The role of DCC as an axon guidance receptor is supported by findings that DCC not only mediates the attractive action by netrin-1 (Keino-Masu et al., 1996; Fazeli et al., 1997) but is also required for the repulsive function of the UNC5 family netrin-1 receptors observed in misexpression experiments (Hong et al., 1999). Antibody directed against DCC receptor can block growth cone repulsion after misexpression of UNC5 in Xenopus embryos (Hong et al., 1999). An interesting question is whether the coexpression of DCC and UNC5 is related to repulsive behaviors in SVZ cell migration. The answer would also reveal the involvement of DCC/UNC5-mediated repulsion in normal biological mechanisms.

\section{Distinct effect of netrin-1 and slit-1 on the migration of striatal SVZ cells}

Our study shows that netrin-1, which is expressed in the striatal VZ, exerts a repulsive action on migrating striatal SVZ cells destined for striatal neurons. Zhu et al. (1999) demonstrated a similar effect on SVZ cells mediated by another protein, slit-1. They suggested that this guidance system is involved in supplying GABAergic interneurons with the cerebral cortex (Zhu et al., 1999). It is interesting that netrin-1 (Figs. 3, 4) and slit-1 (Zhu et al., 1999) appeared to influence distinct subpopulations migrating out of the SVZ explant while they were both localized in the VZ lining. Thus, the redundant expression of netrin-1 and slit-1 in the VZ may play a crucial role in the outward migration of postmitotic cells away from the proliferative zone, which is one of the most essential processes for normal development of the telencephalon.

One may say that, if netrin-1 is the molecular cue essential for 
matrix cell migration, certain histological changes should be found in the striatum of netrin-1-/- mice, as is the case for mice lacking the regulatory genes $D l x 1$ and $D l x 2$ (Anderson et al., 1997b). Unfortunately, this issue is still undetermined. The data available at present show that, in the phenotypes of netrin-1deficient mice, the size of their striatum was decreased by $2.5 \%$; however, no detailed histological findings were presented (Serafini et al., 1996; Braisted et al., 2000). Although analysis of the netrin-1-deficient mice revealed gross normal parameters of striatal development, it has not been concluded that netrin-1 may play a role in the modulation of other neuronal properties but not in the matrix cell migration. As suggested by brain development (Shastry, 1995), the absence of a protein can be compensated by overexpression of other proteins with analogous functions; plural signaling pathways may serve and confirm biologically essential processes.

\section{An additional possible role of netrin-1 in striatal development}

A characteristic feature of the netrin-1 expression patterns in the developing striatum is that the expression is detected throughout the postmitotic area, especially in the ventrolateral region (Fig. $2 A, B$ ) (Serafini et al., 1996; Livesey and Hunt, 1997; Metin et al., 1997; Richards et al., 1997). It is unlikely that this expression of netrin-1 effectively dams the influx of matrix neurons because they are intermingled with early-born patch neurons in the embryonic striatum (Krushel et al., 1995). This inter-mixture is partly because of the downregulation of DCC expression in the striatal postmitotic area (Fig. 2D). What role then does netrin-1 in the postmitotic region play in striatal development? Given that DCC is abundantly expressed in the neocortex (Gad et al., 1997) and the substantia nigra (Livesey and Hunt, 1997), it is possible that netrin- 1 in the postmitotic area is involved in the formation of striatal afferent connections during the embryonic stage. Furthermore, it has been proposed that netrin-1 expression in a more caudal position of the embryonic striatum promotes the growth of thalamocortical projections (Braisted et al., 2000).

Another possibility is that netrin-1 may play a role in striatal cell arrangement during the early postnatal stage. Our histological data demonstrated that the site of netrin- 1 expression in the postmitotic area corresponds with the area in which early-born patch cells clustered (Fig. 2B,E). Netrin-1 expression increases in the neonatal striatum (Livesey and Hunt, 1997). Concerning the putative mechanism or mechanisms underlying the formation of striatal compartments, the selective self-adhesion property of patch neurons in vitro is noteworthy (Krushel et al., 1995). These investigators proposed that, after the transient intermixture of the two neuron phenotypes in the late embryonic stage, they segregate to form distinct compartments in the postnatal stage and that this segregation is mediated by the self-adhesion characteristic of patch cells. One of the candidate chemical cues involved in this clustering is netrin-1; patch neurons may attract the same neuronal phenotype via the secretion of netrin-1 and undergo homogenous aggregation. This hypothesis is supported by the molecular property of netrin-1, homology of the $\mathrm{N}$ termini with portions of the cell adhesion molecule laminin (Serafini et al., 1994). As the aggregation of patch neurons progresses, the netrin-1 concentration probably increases around the forming patch compartments. In this case, the repulsive action of netrin-1 on matrix cells that we documented here may serve to drive these cells to segregate from the patch compartments. We plan to examine the presence of differential responses of patch and matrix neurons to netrin-1 and to determine whether there are anomalous patterns in the striatal compartments of netrin-1-mutant mice.

\section{REFERENCES}

Alcantara S, Ruiz M, De Castro F, Soriano E, Sotelo C (2000) Netrin 1 acts as an attractive or as a repulsive cue for distinct migrating neurons during the development of the cerebellar system. Development 127:1359-1372.

Alexander GE, Crutcher MD (1990) Functional architecture of basal ganglia circuits: neural substrates of parallel processing. Trends Neurosci 13:266-271.

Anderson SA, Eisenstat DD, Shi L, Rubenstein JL (1997a) Interneuron migration from basal forebrain to neocortex: dependence on Dlx genes. Science 278:474-476.

Anderson SA, Qiu M, Bulfone A, Eisenstat DD, Meneses J, Pedersen R, Rubenstein JL (1997b) Mutations of the homeobox genes Dlx-1 and Dlx-2 disrupt the striatal subventricular zone and differentiation of late born striatal neurons. Neuron 19:27-37.

Bhide PG (1996) Cell cycle kinetics in the embryonic mouse corpus striatum. J Comp Neurol 374:506-522.

Bishop GA, Chang HT, Kitai ST (1982) Morphological and physiological properties of neostriatal neurons: an intracellular horseradish peroxidase study in the rat. Neuroscience 7:179-191.

Bloch-Gallego E, Ezan F, Tessier-Lavigne M, Sotelo C (1999) Floor plate and netrin-1 are involved in the migration and survival of inferior olivary neurons. J Neurosci 19:4407-4420.

Braisted JE, Catalano SM, Stimac R, Kennedy TE, Tessier-Lavigne M, Shatz CJ, O'Leary DDM (2000) Netrin-1 promotes thalamic axon growth and is required for proper development of the thalamocortical projection. J Neurosci 20:5792-5801.

Colamarino SA, Tessier-Lavigne M (1995) The axonal chemoattractant netrin-1 is also a chemorepellent for trochlear motor axons. Cell 81:621-629.

Deacon TW, Pakzaban P, Isacson O (1994) The lateral ganglionic eminence is the origin of cells committed to striatal phenotypes: neural transplantation and developmental evidence. Brain Res 668:211-219.

De Carlos JA, Lopez-Mascaraque L, Valverde F (1996) Dynamics of cell migration from the lateral ganglionic eminence in the rat. J Neurosci 16:6146-6156.

Fazeli A, Dickinson SL, Hermiston ML, Tighe RV, Steen RG, Small CG, Stoeckli ET, Keino-Masu K, Masu M, Rayburn H, Simons J, Bronson RT, Gordon JI, Tessier-Lavigne M, Weinberg RA (1997) Phenotype of mice lacking functional Deleted in colorectal cancer (Dcc) gene. Nature 386:796-804.

Gad JM, Keeling SL, Wilks AF, Tan SS, Cooper HM (1997) The expression patterns of guidance receptors, DCC and Neogenin, are spatially and temporally distinct throughout mouse embryogenesis. Dev Biol 192:258-273.

Gerfen CR (1992) The neostriatal mosaic: multiple levels of compartmental organization in the basal ganglia. Annu Rev Neurosci 15:285-320.

Goto S, Matsukado Y, Miyamoto E, Yamada M (1987) Morphological characterization of the rat striatal neurons expressing calcineurin immunoreactivity. Neuroscience 22:189-201.

Goto S, Yamada K, Oyama T, Korematsu K, Nagahiro S, Ushio Y, Fukunaga K, Miyamoto E, Hofer W (1994) Cellular localization of type II $\mathrm{Ca}^{2+} /$ calmodulin-dependent protein kinase in the rat basal ganglia and intrastriatal grafts derived from fetal striatal primordia, in comparison with that of $\mathrm{Ca}^{2+}$ /calmodulin-regulated protein phosphatase, calcineurin. Neuroscience 62:695-705.

Graybiel AM (1990) Neurotransmitters and neuromodulators in the basal ganglia. Trends Neurosci 13:244-254.

Halliday AL, Cepko CL (1992) Generation and migration of cells in the developing striatum. Neuron 9:15-26.

Hamasaki T, Goto S, Nishikawa S, Ushio Y (2001) Early-generated preplate neurons in the developing telencephalon: inward migration into the developing striatum. Cereb Cortex, in press.

Hong K, Hinck L, Nishiyama M, Poo MM, Tessier-Lavigne M, Stein E (1999) A ligand-gated association between cytoplasmic domains of UNC5 and DCC family receptors converts netrin-induced growth cone attraction to repulsion. Cell 97:927-941.

Honig MG, Hume RI (1986) Fluorescent carbocyanin dyes allow living neurons of identified origin to be studied in long-term cultures. J Cell Biol 103:171-187.

Hopker VH, Shewan D, Tessier-Lavigne M, Poo M, Holt C (1999) Growth-cone attraction to netrin-1 is converted to repulsion by laminin-1. Nature 401:69-73.

$\mathrm{Hu} \mathrm{H}$, Rutishauser U (1996) A septum-derived chemorepulsive factor for migrating olfactory interneuron precursors. Neuron 16:933-940.

Johnston JG, Gerfen CR, Haber SN, van der Kooy D (1990) Mechanisms of striatal pattern formation: conservation of mammalian compartmentalization. Dev Brain Res 57:93-102.

Kakita A, Goldman JE (1999) Patterns and dynamics of SVZ cell mi- 
gration in the postnatal forebrain: monitoring living progenitors in slice preparations. Neuron 23:461-472.

Keino-Masu K, Masu M, Hinck L, Leonardo ED, Chan SS, Culotti JG, Tessier-Lavigne M (1996) Deleted in Colorectal Cancer (DCC) encodes a netrin receptor. Cell 87:175-185.

Kennedy TE, Serafini T, de la Torre JR, Tessier-Lavigne M (1994) Netrins are diff usible chemotropic factors for commissural axons in the embryonic spinal cord. Cell 78:425-435.

Krushel LA, Fishell G, van der Kooy D (1995) Pattern formation in the mammalian forebrain: striatal patch and matrix neurons intermix prior to compartment formation. Eur J Neurosci 7:1210-1219.

Lambert de Rouvroit C, Goffinet AM (1998) The reeler mouse as a model of brain development. Adv Anat Embryol Cell Biol 150:1-106.

Livesey FJ, Hunt SP (1997) Netrin and netrin receptor expression in the embryonic mammalian nervous system suggests roles in retinal, striatal, nigral, and cerebellar development. Mol Cell Neurosci 8:417-429.

Marín O, Anderson SA, Rubenstein JLR (2000) Origin and molecular specification of striatal interneurons. J Neurosci 20:6063-6076.

Metin C, Deleglise D, Serafini T, Kennedy TE, Tessier-Lavigne M (1997) A role for netrin-1 in the guidance of cortical efferents. Development 124:5063-5074.

Misson JP, Edwards MA, Yamamoto M, Caviness Jr VS (1988) Identification of radial glial cells within the developing murine central nervous system: studies based upon a new immunohistochemical marker. Dev Brain Res 44:95-108.

Nomura S (1994) In situ hybridization. In: Non-radioisotope experiment protocol: DIG hybridization (Nomura S, Inazawa J, eds), pp 71-82. Tokyo: Shujunsha.

Oyama T, Goto S, Nishi T, Sato K, Yamada K, Yoshikawa M, Ushio Y (1995) Immunocytochemical localization of the striatal enriched protein tyrosine phosphatase in the rat striatum: a light and electron microscopic study with a complementary DNA-generated polyclonal antibody. Neuroscience 69:869-880.

Rakic P (1990) Principles of neural cell migration. Experientia 46:882-891.

Richards LJ, Koester SE, Tuttle R, O’Leary DDM (1997) Directed growth of early cortical axons is influenced by a chemoattractant released from an intermediate target. J Neurosci 17:2445-2458.

Serafini T, Kennedy TE, Galko MJ, Mirzayan C, Jessell TM, TessierLavigne M (1994) The netrins define a family of axon outgrowthpromoting proteins homologous to C. elegans UNC-6. Cell 78:409-424.

Serafini T, Colamarino SA, Leonardo ED, Wang H, Beddington R, Skarnes WC, Tessier-Lavigne M (1996) Netrin-1 is required for com- missural axon guidance in the developing vertebrate nervous system. Cell 87:1001-1014.

Shastry BS (1995) Genetic knockouts in mice: an update. Experientia $51: 1028-1039$.

Sheth AN, Bhide PG (1997) Concurrent cellular output from two proliferative populations in the early embryonic mouse corpus striatum. J Comp Neurol 383:220-230.

Shirasaki R, Tamada A, Katsumata R, Murakami F (1995) Guidance of cerebellofugal axons in the rat embryo: directed growth toward the floor plate and subsequent elongation along the longitudinal axis. Neuron 14:961-972.

Shirasaki R, Mirzayan C, Tessier-Lavigne M, Murakami F (1996) Guidance of circumferentially growing axons by netrin-dependent and -independent floor plate chemotropism in the vertebrate brain. Neuron 17:1079-1088.

Shirasaki R, Katsumata R, Murakami F (1998) Change in chemoattractant responsiveness of developing axons at an intermediate target. Science 279:105-107.

Sussel L, Marín O, Kimura S, Rubenstein JL (1999) Loss of Nkx2.1 homeobox gene function results in a ventral to dorsal molecular respecification within the basal telencephalon: evidence for a transformation of the pallidum into the striatum. Development 126:3359-3370.

Tessier-Lavigne M, Goodman CS (1996) The molecular biology of axon guidance. Science 274:1123-1133.

van der Kooy D, Fishell G (1987) Neuronal birthdate underlies the development of striatal compartments. Brain Res 401:155-161.

Wichterle H, Garcia-Verdugo JM, Herrera DG, Alvarez-Buylla A (1999) Young neurons from medial ganglionic eminence disperse in adult and embryonic brain. Nat Neurosci 2:461-466.

Wu W, Wong K, Chen J, Jiang Z, Dupuis S, Wu JY, Rao Y (1999) Directional guidance of neuronal migration in the olfactory system by the protein Slit. Nature 400:331-336.

Yamada K, Goto S, Yoshikawa M, Ushio Y (1996) GABAergic transmission and tyrosine hydroxylase expression in the nigral dopaminergic neurons: an in vivo study using a reversible ischemia model of rats. Neuroscience 73:783-789.

Yee KT, Simon HH, Tessier-Lavigne M, O'Leary DDM (1999) Extension of long leading processes and neuronal migration in the mammalian brain directed by the chemoattractant netrin-1. Neuron 24:607-622.

Zhu Y, Li H, Zhou L, Wu JY, Rao Y (1999) Cellular and molecular guidance of GABAergic neuronal migration from an extracortical origin to the neocortex. Neuron 23:473-485. 